\title{
A IMAGINAÇÃO POÉTICA E O PROJETO ESTÉTITO DE LÍLIA A. PEREIRA DA SILVA
}

\author{
Antonio Donizeti da Cruz (UNIOESTE)
}

RESUMO: Este trabalho tem como objetivo apresentar o universo imaginário e o projeto estético de Lília A. Pereira da Silva, que revela um conjunto de imagens recorrentes em sua obra: mulher, espelhos, natureza, carnaval, palhaçoes, entre outras. Lília A. Pereira da Silva nasceu em Itapira (SP). É escritora, poeta, pintora, desenhista e ilustradora de livros. Tem publicado noventa e dois livros nas áreas de poesia, romance, literatura infantil, artes plásticas e didáticos. Como artista plástica e desenhista, ela tem realizado quase 300 mostras. Pretende-se analizar a obra da Autora, com fundamentação na teoria do imaginário, semiótica e mitocrítica. O universo imaginário, na obra de Lília, é espaço aberto no qual a poeta concretiza sua visão da vida e imagem do mundo. PALAVRAS-CHAVE: Lília Pereira da Silva - poesia - imaginário

"É pela intencionalidade da imaginação poética que a alma do poeta encontra a abertura consciencial de toda a verdadeira poesia". Gaston Bachelard.

Lília A. Pereira da Silva é escritora, poeta, pintora, desenhista, capista e ilustradora de livros. Publicou noventa e dois livros nas áreas de poesia, romance, literatura infantil, artes plásticas, didáticos de Direito, de Psicologia e Artes Plásticas. Alguns dos títulos publicados pela Autora:Desenho e Pintura (2002), Carnaval Brasil (1996, $2^{\text {a }}$ ed.), Elipses do anjo (1993), Cartas à minha sombra(1997), Álbum de mim nиa (1997), Mínimos Conceitos (poesias) e Contos Abstratos(1994), Europeanas (1997, $3^{a}$ ed.), entre outros. Lília A. Pereira da Silva nasceu em Itapira (SP). Reside em São Paulo. Foi professora de pintura e de piano, tendo participado de concertos. Cursou Secretariado, Jornalismo, Direito e Psicologia. Representou o Brasil em poesia, em Toluca (México), em 1972, e em Artes Plásticas, em Santiago (Chile), em 1974. Instituiu um prêmio anual, desde 1995, de Poesia e Desenho, com apoio da Prefeitura Municipal, Câmara Municipal de Esportes, Cultura e Turismo de Itapira, SP. Ilustradora e capista de livros nacionais e estrangeiros, Lília A. Pereira da Silva possui livros de suas poesias versadas em 8 línguas: inglês, francês, espanhol, italiano, japonês, latim, norueguês e alemão.

A artista Lília tem realizado quase 300 mostras (pintura e desenho). Recebeu um grande número de prêmios nacionais e internacionais (Battipaglia - Itália, México (D.F.), Roma, Paris, entre outros). Tem participado também de inúmeras antologias no Brasil e no exterior. Em relação às artes plásticas, suas obras encontram-se em museus brasileiros e estrangeiros (U.S.A, México, Holanda, França, Itália, Mônaco, Chile). Desenvolve uma técnica que vai desde o acrílico, esmalte, óleo, purpurina, colagem, tela, alumínio, papéis diversos, aquarela, ao guache (entre outros materiais). Suas obras vão do figurativo ao abstracionismo, revelando também ousadas técnicas expressionistas e surrealistas, com uma obra que revela manifestações e dramas humanos. 


\section{IMAGINÁRIO, POESIA E CONTEMPLAÇÃO}

A poesia e as artes em geral são potências capazes de dar sentido à vida. Ao bu scar a essência da linguagem, o artista realiza o poder mágico através das palavras, das formas e cores: ser mediação, comunicação, exercício de construção de sentidos. Nesse sentido, Javier González afirma que a palavra é sempre uma "manifestação profunda do ser" (1990: 156). Para o autor, mediante o universo poético, o poeta se apóia nos aspectos lúdicos, rítmicos e imaginários da linguagem, cuja função poética funciona como um vetor constitutivo da natureza humana. É pela palavra que o homem se coloca no plano expressivo superior a não-significação da ordem natural, pois ela, enquanto núcleo de dispersão e convergência, é capaz de nomear o mundo (GONZÁLEZ 1990: 152-153).

González considera o trabalho do poeta como um desenvolvimento frente aos meios de fixação e dispersão de sentido, ou seja, como um jogo de palavras que tem por finalidade projetar um grande número de significações. Dessa forma, o escritor descobre e constrói o mundo utilizando a palavra enquanto instrumento "capaz de conter a surpreendente variedade do real", isto é, ele sabe que o uso da linguagem abre múltiplos espaços de "comunicação e de nominação dos objetos" (GONZÁLEZ 1990: 156-157).

Ao se referir à imaginação poética, Javier González salienta que as imagens têm sentido em distintos níveis, primeiramente, deve-se considerá-las autênticas e universais. Há as imagens arquetípicas que se revelam espontâneas e da mesma forma a todos os homens, ou seja, "são elementos fundamentais que podem descrever como categorias primárias da produção imaginária" (GONZÁLEZ 1990: 180). Existem ainda as que constituem uma realidade mental que se aproxima solidariamente aos objetos do mundo, isto é, elas constituem "um sistema cognitivo, com uma lógica particular. A seqüência das imagens, em contraste com o discurso, implica na equivalência das partes. Cada imagem constitui o universo em sua totalidade, e seus desdobramentos são um enriquecimento sobre o plano expressivo e não simplesmente informativo" (GONZÁLEZ 1990: 181). É dessa forma, no dizer do autor, que a relação analógica entre a imagem e o mundo fenomenológico confere àquelas um estatuto e forma um encadeamento semelhante às que unem as idéias e os conceitos no pensamento discursivo.

Para Javier del Prado, em Teoria y prática de la función poética: poesía siglo XX, a imaginação está limitada pela realidade, ou seja, "não se pode imaginar o que não existe; ela necessita de objetos, números, paisagens, planetas e se fazem precisas as relações entre os eles dentro da lógica pura. Não se pode saltar no abismo nem prescindir dos termos reais. A imaginação tem horizontes, quer desenhar e concretizar tudo que o que alcança” (PRADO 1993: 13).

No dizer de Prado, a imaginação poética viaja e transforma as coisas, lhe dá seu sentido mais puro e define relações que não se suspeitavam, mas sempre opera sobre fatos da realidade mais nítida e precisa (PRADO 1993: 13). E complementa:

Esta relação com a imaginação poética com a realidade e com a lógica, esta necessidade que tem a imaginação poética de concretizar e desenhar horizontes, permitem ao crítico 
[...] buscar referentes: pedras angulares no cruzamento de uma lógica ou uma analógica imaginárias que explicam, não as razões secretas (mistérios do eu criador sempre silencioso), mas sim os mecanismos e seus efeitos que têm como matriz a realidade e como semente fecunda e fecundante a imaginação poética (PRADO 1993: 13; grifos do autor).

Por sua vez, Luis Racionero, em $\mathrm{El}$ arte de escribir, salienta que o homem cria estruturas, relações, a partir de elementos preexistentes, pois a criatividade consiste em conectar estruturas mentais. Se uma conexão tal como se expressa mediante uma forma, causar emoção no espectador, se diz que é arte. A arte compõe entidades artificiais previamente inexistentes:golems de palavras, labirintos de imagens, mármores de pedra e cores, sons ou gestos, combinando esses materiais com o objetivo de intensificar a experiência e provocar profundas emoções para distinguir certas composições de ações fluentes, distinção que hoje em dia é mais necessária que nunca (RACIONERO 1995: 15-16).

Por se encontrar no nível mais alto da escala das experiências mentais, a imaginação, no dizer de Racionero, se forma a partir dos materiais proporcionados e armazenados por outros níveis: sensações oriundas dos sentidos, suas correspondentes imagens mentais, alucinações produzidas pela combinação errática destas no circuito neuronais e na memória. A imaginação criativa atua por onirosíntesis (sonhos-síntese), nos lapsos da percepção, graças ao trabalho zelosamente oculto que se efetua na substância dos circuitos neuronais (RACIONERO 1995: 48-50). Por sua vez, a memória evoca imagens, a fantasia as combina fora das leis da natureza; a imaginação as molda em combinações orgânicas materializáveis na prática. A fantasia é uma simples justaposição de elementos incongruentes que formam uma quimera. Já o produto da imaginação contrasta com a realidade e por isso permanece e dura. A fantasia é a combinatória da imaginação, salienta Racionero.

Para Gaston Bachelard, a imaginação não é, como sugere a etimologia, "a faculdade de formar imagens da realidade; é a faculdade de formar imagens que ultrapassam a realidade, que cantama realidade" (1989: 18; grifo do autor). Mais do que inventar coisas e dramas, a imaginação "inventa vida" e "mente novas". O filósofo define a imaginação como uma potência máxima da natureza humana. A imaginação, com sua "atividade viva", desvincula-se, simultaneamente, do passado e da realidade, direcionando-se para o para o futuro. Nesse sentido, a "fenomenologia da imaginação" não se contenta "com uma redução que transforma as imagens em meios subalternos de expressão". Ela "exige que vivamos diretamente as imagens, que as consideremos como acontecimentos súbitos da vida. Quando a imagem é nova, o mundo é novo" (BACHELARD 1993:

$63)$.

Gilbert Durand define o imaginário como o "conjunto das imagens e relações de imagens que constitui o capital pensado pelo homo sapiens" (1997: 18). Ele é o grande denominador fundamental para onde se convergem "todas as criações do pensamento" (DURAND 1997: 18). O filósofo salienta ainda que, o imaginário humano constitui o conector inevitável pelo qual se forma qualquer representação humana, pois "todo pensamento humano é uma re-presentação, isto é, passa por articulações simbólicas" 
(DURAND 1997: 40-41; grifos do autor). Complementa ainda que, o imaginário institui a priori um "domínio do espírito sobre o mundo", sendo que,

É a objetividade que baliza e recorta mecanicamente os instantes mediadores da nossa sede, é o tempo que distende a nossa saciedade num laborioso desespero, mas é o espaço imaginário que, pelo contrário, reconstitui livremente e imediatamente em cada instante o horizonte e a esperança do Ser na sua perenidade. (DURAND 1997: 433)

Já as imagens, qualquer que seja "o regime a que pertencem, em contato com a duração pragmática e com os acontecimentos, organizam-se no tempo, ou seja, ordenam os instantes psíquicos numa 'história"' (DURAND, 1995, p. 75-76. Grifo do autor).

Se a imaginação é a força dinâmica pela qual o homem consegue imaginar mundos e dar sentido à vida através de imagens, a poesia é o vetor de operacionalização dos instantes vividos, das transmutações da linguagem, da valorização dos sentimentos e das coisas mais simples. É por meio da imaginação e da concretização da poesia que o ser humano consegue dar forma às coisas mais tênues, evanescentes e se auto-afirmar. Sendo assim, a poesia é transcendência, contemplação, força que edifica e revigora o homem frente às vicissitudes da vida.

\section{LIRISMO, VIAGEM E IMAGINAÇÃO POÉTICA EM EUROPEANAS}

A obra Europeanas, de Lília A. Pereira da Silva, reúne 31 poemas que remetem a uma variedade temática que vai do tema da viagem à memória e imaginação. Já os registros feitos pelo sujeito lírico realçam a condição de um eu que observa o mundo, as coisas, as cidades, campos, pessoas e praças e, ao mesmo tempo, revela-se ao refletir sobre a vida, o olhar e a observação atenta da natureza. $O$ tema da viagem é alicerçado por um $\mathrm{Eu}$ que vai registrando as paisagens européias e as cidades: Paris, Madri, Sevilha, Lisboa, Roma, entre outras.

Ao se referir a Europeanas, de Lília A. Pereira da Silva, o escritor francês Claude Cotti, afirma que "Ler Europeanas é viajar para onde ela andou na Europa. Suas poesias são fortes e inesquecíveis, como toda Literatura. Tem-se a impressão de estar vendo telas a óleo, coloridas e musicadas, em cada poesia de seu livro" (COTTI, in: SILVA 1997: contracapa). E complementa: Ela levou o Brasil à Europa e a Europa ao Brasil. Assim, fala [...] da sua muita esperança, da presença dos deuses, da saudade do irmão morto, do Museu do Prado, do Mediterrâneo e Adriático e "esquece as sandálias brancas na rua de Madri, onde perambula com versos de Florbela e de Pessoa". Cita as "Capas de Coimbra, os mochileiros tatuados, os toureiros, Picasso", tudo "ardendo um perfil na sua bandeira brasileira". (COTTI, in: SILVA 1997: contracapa)

Claude Cotti destaca ainda que a maior parte das poesias de Europeanas foram escritas no Café de La Paix, em Paris. Cumpre destacar que o poeta francês traduziu por duas vezes os poemas de Lília. Lília A. Pereira da Silva tem recebido crítica favorável à sua obra de poetas, críticos, artista plásticos, brasileiros e internacionais. Ela tem recebido elogios de Fernando Namora, Carlos Drummond de Andrade, Wilson Martins, entre outros. Sobre Lília, Cecília Meireles afirma: "Lília - a de olhos guardados nas rosas..." ( SILVA 1991). 
Segundo João Alexandre Barbosa, a viagem - para o poeta moderno - não significa somente uma conquista cumulativa de espaços inusitados, mas "a criação de um espaço em que seja possível reduzir a multiplicidade individual da linguagem da poesia aos parâmetros homogêneos da linguagem do poema" (1986: 32). Barbosa lembra que "viagem é linguagem", e destaca que o poeta moderno é sabedor de sua condição de iludido, pois "a procura da consciência nostálgica da eternidade" faz com que ele se lance na busca da conquista do intemporal, porém se vê frente ao transitório, ao fugidio e ao contingente. Ele se imagina intérprete do Homem, e não dos homens, pelo cultivo de uma outra ilusão: a da onipresença.

O motivo da viagem - recorrente na obra Liliana - direciona para uma linha da literatura ocidental que remete à Odisséia de Homero, passa pelas aventuras de Dom Quixote, pelas literaturas de viagem e por tantas outras que tratam desta temática. A viagem na obra de Lilia A. Pereira da Silva tem, muitas vezes, o sentido de travessia e também "introspecção", em que o eu-lírico "mergulha" em si mesmo em busca do eu totalizante. Na circularidade do tempo e do espaço, o sujeito poético faz da viagem convite à busca de sentido vital e descobertas das "paisagens do mundo". Através das palavras, concretiza-se uma "viagem" em que os espaços vazios são preenchidos pelas palavras e sentidos de "travessia", tal como nos versos do poema "Passagem":

Eu, de passagem,

passando.

Só não passa a poesia

- porto de muitas viagens, gosto de estrelas feridas.

(SILVA 1997: 32).

A palavra "viagem" é termo que aparece com freqüência na obra de Lília A. Pereira da Silva, de maneira especial em Europeanas. O sujeito poético, nos versos, concretiza seu estar no mundo e faz do ato de viajar uma potência criadora de descobertas, desvendando espaços inusitados, tal como nos versos do poema "Travessia do Sena", em que o eu-lírico expressa a condição de observador atento:

Barco é altar no Sena,

Derruba lenda, a estrela, no suportável das margens.

$[\ldots]$

Mais lampiões sobre as pontes, ancoradouro, partida.

Faróis tingindo de verde mansas águas que se singra

(espuma de vime e junco).

Canções de ausência mais claras...

E que trêmulo ombro

ampare outro que tenho

nas travessias futuras...

(SILVA 1997: 61-63)

Em "Retrato plural”, o eu lírico realça a constatação de que as cidades são parecidas, 
quer no espaço urbano, na geografia, no comportamento das pessoas, na observação atenta das coisas e nas imagens reiterativas, com versos repletos de lirismo:

Em todas as cidades do mundo,

sofrimento é maior quando não se perdeu

coração em ninguém.

Em todas cidades do mundo,

há roupas estendidas nas paredes

e nudez dentro

das vidraças.

$[\ldots]$

Em todas cidades do mundo há espaços, muros

e sapatos abandonados nas ruas,

tirando retratos do passado

e futuro,

e pombas que exibem asas

e não voam - como outras - acima dos telhados.

Em todas cidades do mundo

há janelas sujas de trem

anuviando paisagem,

$[\ldots]$

Em todas cidades do mundo há ciganos

que revivem esta saudade,

estalando

no meu céu da boca

o grito da vida.

[15.07.88 - De Lisboa a Fátima (SILVA 1997: 7-8)]

O poder da imaginação que direciona a uma abrangência mais ampla, é a tônica que movimenta o poema. Em todas as estrofes, destacam-se os paralelismos sintáticosemântico-sonoros das estrofes iniciadas pelo verso: "Em todas as cidades do mundo". Há a constatação por parte do eu lírico de abandonos, saudades, sofrimentos, contrastes.

Operador de enigmas, o poeta faz da linguagem um espelho de dupla face: de um lado a palavra e do outro o silêncio. Na conjugação das formas dialéticas ele constrói o universo imaginário em que é possível a realização, daí a linguagem do poema ser "revelação". Quer dizer, "a revelação poética pressupõe uma busca interior. Busca que em nada se assemelha à análise ou à introspecção, mais que busca, atividade psíquica capaz de provocar a passividade propícia ao surgimento de imagens” (PAZ 1982: 65).

No poema "Gaivota", o tema da viagem fica latente:

Também pode a gaivota ter mais sonhos:

auréola de pastora, inda vencer

o barco espumarando verde mar.

Constelada de ânsias,

o leme escorre às asas.

Entanto, 
esvoaça-lhe o motor a própria sombra.

Limitada no ser,

inquieta, não sinala porto íntimo,

mas glória de tentar lhe foi cumprida.

[18.07.88 Aeroporto de Lisboa (SILVA 1997: 12)]

Nos versos sobressaem as imagens do "porto", "barco", "gaivota", "mar". São versos marcados por uma linguagem que revela a condição de um eu lírico enquanto observador atento e em constante viagem. Na primeira estrofe, a afirmação do sujeito lírico é categórica ao reportar à gaivota capaz de alçar vôos e sonhar, até mesmo vencer "o barco espumarando verde mar". A segunda estrofe alude à observação atenta da natureza com seus signos vitais, ou seja, as imagens do "leme" e das "asas" fazem alusão à viagem. Na última estrofe a constatação de que a gaivota, mesmo "limitada no ser" é capaz de atingir o mais alto objetivo. A imagem da gaivota - enquanto metáfora pode remeter à condição itinerante do ser humano, "sempre em viagem".

Percebe-se que a poesia liliana reside na busca memorável e densa das palavras e na concretização de um fazer poético enquanto "felicidade da expressão verbal", no dizer de Calvino, que pode efetivar-se mediante "uma fulguração repentina", em alguns casos, mas na maioria das vezes, tal processo implica sempre em "uma paciente procura do mot juste, da frase em que todos os elementos são insubstituíveis, do encontro de sons e conceitos que sejam os mais eficazes e densos de significado" (CALVINO 1990: 61; grifo do autor). Dessa forma, o fazer poético liliano está embasado, essencialmente, na busca da palavra exata para concretizar a comunicabilidade lírica.

No poema "Chovem lírios em meus cabelos", com uma linguagem altamente elaborada, registra os momentos vivenciados pelo sujeito da enunciação:

Chovem lírios em meus cabelos

e é grave a urze no peito.

Nas fontes de pedras, emoções deliram em outras línguas.

Existe fantasia e realidade:

pesadas estátuas

em tênue fio unidas.

Canta no palácio, a menina.

Velha senta na calçada:

gume e flor.

Cisma o Tejo, dorme o Sena, ora e canta Manzanares, rendam-se em rosas de gotas, Mediterrâneo e Adriático.

Vestindo espadas, bandeiras arcoirisando olivais, mulheres de sete saias no bairro das Mourarias cheiram fado nos cabelos, vestem xales de saudade. [...] 
Esqueço sandália branca na rua de Madri.

e perambulando com versos

de Florbela e de Pessoa.

Tantas nacionalidades

solícitas às informações!...

[...]

19.07.88 Madri, Museu do Prado (SILVA 1997: 13)

Note-se, nos versos, uma linguagem metafórica, com imagens sugestivas: "chuva de lírios nos cabelos", "urze no peito" e "cheiro de fado nos cabelos". Há a descrição geográfica de lugares europeus, como o bairro da mouraria, referências aos rios Tejo, Sena, Manzanares, e aos mares Mediterrâneo e Adriático. A personificação é um recurso utilizado pela poeta para realçar e dar dinamismo ao texto.

As rimas, na poesia de Lília A. Pereira da Silva, são recursos fundamentais que suscitam inesperadas alianças de termos, de sentido. Não se trata apenas da sonoridade, musicalidade, mas o que está em jogo é a estrita relação entre som e sentido.

O poeta, através do ato de nomear, de poetizar o mundo e de dar sentido às coisas, faz da linguagem uma viagem em versos. Mediante a atividade criadora, o poeta, enquanto viajante no e do mundo, reafirma sua condição de exilado. Daí a poesia auxiliar o homem no esclarecimento de uma das questões psicológicas mais relevantes: "a determinação do seu próprio ser" (LOTMAN 1978: 119-23). Note-se, nos versos, um sentido vital no que diz respeito à construção do texto relacionada ao jogo de palavras projetando uma "poesia-invenção" que veicula o máximo de informação em um número restrito de palavras.

No poema "Madri", o sujeito da enunciação observa a paisagem e referências citadinas:

Madri no rastro do poente.

Primavera

em meus cabelos brancos...

Inda cantam

as capas de Coimbra

e ciganas de negro,

retratando lâminas

nas mãos.

Mochileiros tatuados

entre xales e babados.

Mulheres jovens,

exaustas de emoção.

[...]

Toureiros brilham ouro nos brincos,

entre sirenas.

[...]

Cisnes comungam peixes pelas praças,

sem mais o Douro

esvoaçando

à vidraça.

Estrela morde o dia.

Picasso mostra homens por dentro. 
$[\ldots]$

Aqui, como em toda cidade do universo,

atenta às manhãs e madrugadas,

resumo que poetas e heróis

só valem se em morte resumidos.

[20.07.88 Caminho para Toledo, Espanha (SILVA,1997: 16-17)]

Note-se, nas passagens, a essência fundamental da poesia liliana, que reside na harmonia e na beleza com que organiza seus poemas, quer dizer, nesse "universo" de relações recíprocas entre os "sons" - a musicalidade, o ritmo, o movimento, o timbre, a entonação, a voz transmudada em ação - e os "significados" - as idéias, as imagens, as excitações do sentimento e da memória e as formações de compreensão, como nos versos: "Estrela morde o dia", "Touros brilham ouro nos brincos", "Cisnes comunga peixes nas praças". Através dessas relações, o poeta cria seu universo poético operacionalizando a linguagem no sentido de que fala Paul Valéry: o poema "não morre por ter vivido: ele é feito expressamente para renascer de suas cinzas e vir a ser indefinidamente o que acabou de ser. A poesia reconhece-se por esta propriedade: ele tende a se fazer reproduzir em sua forma, ela nos excita a reconstruí-la identicamente" (VALÉRY 1991: 213).

Em "Flash de mim na estrada", o tema da viagem mais uma vez ganha dimensão na enunciação do sujeito lírico:

Percebo, no infinito,

tantas cismas comovidas;

ando por onde não fui

e fui por onde não ando!

Estremeço em cada passo, nos pedaços da estrada, somada de tantos auges, ao próximo adaptada.

Viajo como em mim, no mistério de mil quilhas, vendo hoje, vendo ontem e só de mim não segura - indefinido prenúncio de que sou muito e sou nada.

Se me enfeitam saudades, mais me enfeitam estradas. Em mim murmura volúpia das coisas apagadas

Hoje fui um girassol; a manhã, rosa-dos-ventos. Já fui deserto e fui água. Só não fui a que não sou. E não serei apagada. 25.07.88 Caminho para Granada (SILVA 1997: 28)

São versos que remetem ao tema da viagem enquanto busca e que mostram a imaginação do sujeito poético, capaz de articular a linguagem de maneira lúdica. Há, 
nos versos, o sentido de procura: o eu em busca de si mesmo e do outro. O sujeito lírico expressa sua condição de viajante solitário, ao declarar que viaja "no mistério de mil quilhas, / vendo hoje, vendo ontem / [...] - indefinido prenúncio / de que sou muito e sou nada." (SILVA 1997: 28).

O universo poético liliano articula-se através da multiplicidade das imagens de um eu que se desdobra verso a verso, das imagens e figuras densas, das consonâncias e dissonâncias dos versos com seus ritmos bem acentuados.

O tema e o movimento vital da viagem - na obra Lília A Pereira da Silva - faz com que o sujeito poético se volte ao tempo passado e também se lance ao tempo futuro. Para Erico Verissimo, o ser humano viaja por dois motivos básicos: "para fugir ou para buscar. Os fugitivos cedo ou tarde descobrem que seus problemas são de natureza geográfica" (VERISSIMO 1999: 145). Nesse sentido, a viagem não é só um processo de redescoberta, mas uma experiência que se realiza no plano pessoal e espacial.

Mediante o ato imaginativo, Lilia A Pereira da Silva concretiza uma poesia que é mediação solidária com o leitor, ou seja, sua voz "participativa" abre múltiplos espaços de interlocução. A poesia liliana aponta para a experiência cotidiana e transcende-a mediante a imagem poética, que se reporta a uma dimensão maior, despertando no leitor um sentimento de plenitude e fascinação perante as palavras. Assim, a poesia é uma forma de auto-revelação, que permite um constante "recriar-se e recriar-nos", pois conforme Octavio Paz, ela "é um tecido de conotações, feita de ecos, reflexos e correspondências entre som e sentido" (1991: 151). Esta afirmativa do autor pode ser constatada no poema "Passagem", em que o eu-lírico afirma:

Sol de estanho na cama e meu cavalo de sombra. Estrelas de pergaminho e reluzente carinho na minha pele tão só.

Sol de estanho na cama e meu cavalo de sombra. Ao longe, flauta entornada, ébrios pandeiros ciganos em pátios só muçulmanos em Alicante e Granada.

Sol de estanho na cama e meu cavalo de sombra. $\mathrm{Eu}$, de passagem, passando. Só não passa a poesia - porto de muitas viagens, gosto de estrelas feridas. [27.07.88 Caminho para Valença (SILVA 1997: 32) ]

Os versos realçam a temática da viagem, que remete ao sentido de introspecção, de subjetividade e busca de si mesmo. Na esfera vital, de tantas travessias, o eu se desdobra verso a verso, num esforço de autocompreensão realizando uma viagem que se processa na busca de si mesmo e na busca do outro. Viajar por mundos imaginários é uma 
maneira de amenizar "as paisagens do mundo" nem sempre belas, nem sempre harmoniosas.

A poesia é definida como "porto de muitas viagens". Da imaginação do poeta surge uma linguagem metafórica, lúdica, como nos versos:

Sol de estanho na cama

e meu cavalo de sombra.

Estrelas de pergaminho

e reluzente carinho

na minha pele tão só.

Na passagem fica evidência a solidão vivenciada pelo eu lírico. Já o poema - sinal de "quase-permanência" num mundo transitório - acaba por ser expressão da consciência de um sujeito que faz da imaginação uma viagem inusitada através da linguagem. $O$ poeta se volta à experiência poética no afã de atingir o equilíbrio e a contenção da linguagem, pois na procura mais essencial da palavra para transmitir uma emoção, ele nomeia as coisas criando uma nova realidade. No poema "Toureiro descalço", as imagens do touro e da noite aparecem interligadas:

Noite é touro vermelho como o que vi na tourada. Matador veste azul para esconder a espada.

Noite é touro vestido de sangue e de cansaço... Tantos toureiros chegaram, se somaram e se somaram com duas armas do Poder - espadas que se ampararam. [...]

A noite é grande touro com pés escorrendo sangue. Mundo, na arquibancada, paga a sentir emoção.

Só touro não entende palmas que são para ele morrer. Ai, toureiro! Em tua capa são micas chifres de touro e tento não padecer!...

Noite é touro vermelho Como o que vi na tourada... [28.07.88 Caminho para Barcelona (SILVA 1997: 33-34) ]

As imagens da noite, touro e toureiro são realçadas no texto. A noite (metáfora de morte) é definida como "touro vermelho". Há o contraste das cores azul e vermelho: toureiro (matador) vestido de azul X noite vestida "de sangue e cansaço". Conforme Chevalier e Gueerbrant, a imagem do touro "evoca a idéia de irresistível força e arrebatamento" e é símbolo da "força criadora" e é considerado, portanto, "um animal lunar, relacionado com a noite" (2002: 890-892). Note-se que a imagem é "palavra articulada", no dizer de Alfredo Bosi. Assim, touro e noite estão (inter)relacionadas no 
poema (BOSI 2000: 19). Para Bosi, a imagem "é afim à sensação visual. O ser vivo tem, a partir do olho, as formas do sol, do mar, do céu. O perfil, a dimensão, a cor. A imagem é um modo da presença que tende a suprir o contato direto e a manter, juntas, a realidade do objeto em si e a sua existência em nós" (BOSI 2000: 19).

No poema "Elos", as confluências de vozes ficam evidenciadas. O poema apresenta a cidade de Florença "acordada de sinos", a voz do camelô: "Loteria de Veneza", e a firmação do eu lírico ao dizer que passou o "domingo escrevendo / nos túneis voadores". Há também as lembranças de Barcelona, dos "mercadores de pássaros", "a orelha cortada de touro", e a ampla geometria das coisas e descrição dos lugares, como nas passagens:

Espuma de petúnias...

Árvores bailarina.

Pavões, estalactites

E licores de Maiorca

[...]

Leões, brasões, azulejos,

Muralhas-cedro e pérolas,

aveia, cevada, trigo,

Granada, Málaga, Palma.

E sinos-açucenas

do convento de Cartuja.

Cidades, cidades tantas!

[09.08.88 - Sobrevoando Paris - (SILVA 1997: 50-51)].

As imagens, nos versos dos poemas, direcionam, muitas vezes, para as coisas que só uma mente aberta à contemplação da natureza pode observar. Das impressões de viagens e dos registros de novas descobertas pelo sujeito lírico por estar conhecendo tantas cidades européias, faz a seguinte afirmação:

Também tenho uma cidade que é cela das estrelas do pensamento só meu. No seu eixo imaginário, tem balcão de arcanjo. E se a seara é errante, vive a alfazema do instante de apagadas arenas.

Uma característica peculiar da poeta Lília é sua disciplina espiritual, sua maneira de ver o mundo com "os olhos da imaginação". Ao projetar sua consciência artística, em que reúne técnica poética aliada a uma inteligência crítica, ela dá forma e procedimento artístico e poético à sua arte.

Os versos do poema "Imagem", realçam a questão do olhar e das coisas que ocorrem ao redor do sujeito lírico atento às paisagens:

Ai, castanholas de sóis

e rosas de fel na boca!

$\mathrm{Ai}$, viagens ao redor

da janela que não eu!... 
Convencer-me a cada instante

que, em toda despedida

das cidades que conheço,

um fim pode ser começo!...

Ai Múrcia, mica e verde, distante das odaliscas, leões, sultões, magnólias, tanto oásis de Granada!

Onde guitarras ébrias

de fantasmas e fantasmas

e poesias escritas

nas paredes de Alhambra?

Ai, tempo que faz promessas,

ai, tempo que faz surpresas!

Às vezes abraço o sol,

às vezes cai minha estrela!...

[03.08.88 Roma (SILVA 1997: 33-34)]

A repetição do tema da viagem aponta para a esperança e certeza de que as palavras têm o poder de despertar o homem para o sonho, para iniciar a busca e chegar à realização, mesmo que, às vezes, o tempo traga "promessas" $\mathrm{e}$ "surpresas. A remissão constante ao tema da viagem relaciona-se à procura do eu em permanente busca de si mesmo, reporta às mais diversas formas de desdobramento do sujeito lírico sempre à procura de algo que dê sentido à vida, tal como afirma o sujeito lírico, nos verso do poema "Gosto de cicatriz": "Perto de mim, sem viver, / esta busca, esta busca / e gosto das cicatrizes / das batalhas invisíveis / que só o silêncio as tem" (SILVA 1997: 49). A poeta projeta um mundo de descobertas e experimentações com a linguagem, feita de sons, silêncios e sentidos.

A temática da viagem, na poesia de Lília A Pereira da Silva, remete para a busca e para a redescoberta de um centro espiritual. A viagem simboliza a busca do plano transcendente. Exprime ainda, "um desejo profundo de mudança interior, uma necessidade de experiências novas, mais do que um deslocamento físico. Segundo Jung, indica uma insatisfação que leva à busca e descoberta de novos horizontes" (CHEVALIER \& GHEERBRANT 2002: 952).

A viagem - na poesia Liliana - ocorre enquanto busca, isto é, expressa todo um sentimento e toda uma afirmação do sujeito poético ao se situar no tempo e espaço. Através da viagem em versos e das operacionalizações articuladas pela linguagem, o poeta se vê inserido nas múltiplas facetas espaço-temporais. A viagem ganha, assim, uma dimensão de destaque de um eu que está em "viagem" permanente.

Em Europeanas, há um universo de recordações que apontam para lugares e espaços vitais. Através da linguagem poética, enquanto viagem e travessia, Lília A. Pereira da Silva rememora impressões de viagens e recupera fatos e momentos vividos no exercício poético e imaginário.

Na obra de Lília A. Pereira da Silva, as formas do imaginário não são simples temas. Elas ocorrem entrelaçadas quer às obras literárias quer às pictóricas no universo liliano, 
que registra imagens alicerçadas nos "registros-chave", que direcionam para um cuidadoso processo de escritura e elaboração "poético-pictórica" alicerçados na imaginação poética.

Pode-se concluir que a construção poética e o projeto estético liliano residem nos procedimentos e nas formas escolhidas, nos ritmos, no enxugamento dos textos, "nas pinceladas poéticas" de palavras, cores e formas. Seus poemas registram o teor de modernidade e contemporaneidade. Na poesia de Lília verifica-se a preocupação do eu poético em relação à elaboração precisa da linguagem, registrada na maneira de interpretar o mundo e as coisas. Com sua maneira própria de atuação, a poeta apresenta $\mathrm{o}$ ato criador como um exercício e comprometimento perante a vida e a arte, mediante a efetivação de um pensamento capaz de (re)inventar universos imaginários.

\section{OBRAS CITADAS:}

BACHELARD, Gaston. 1989. A água e os sonhos: ensaios sobre a imaginação da matéria. São Paulo: Martins fontes.

—. A poética do devaneio. São Paulo: Martins Fontes.

BARBOSA, João Alexandre. 1986. As ilusões da modernidade. São Paulo:

Perspectiva.

BOSI, Alfredo. 2000. O ser e o tempo da poesia. São Paulo, Companhia das Letras.

CALVINO, Ítalo. 1990. Seis propostas para o próximo milênio. São Paulo: Companhia das Letras.

CHEVALIER, Jean \& GHEERBRANT, Alain. 2002. Dicionários de símbolos. Rio de Janeiro: José Olympio.

DURAND, Gilbert. 1995. A imaginação simbólica. Lisboa: Edições 70, 1995.

—. 1997. As estruturas antropológicas do imaginário: introdução à arquetipologia geral. São Paulo: Martins Fontes.

GONZÁLEZ, Javier. 1990. El cuerpo y la letra: la cosmología poética de Octavio Paz. México: Fondo de Cultura Económica.

LOTMAN, Iuri. 1978. A estrutura do texto artístico. Lisboa: Editorial Estampa.

PAZ, Octavio. 1982. O arco e a lira. Rio de Janeiro: Nova Fronteira.

—. 1991. Convergências: ensaios sobre arte e literatura. Rio de Janeiro: Rocco.

PRADO, Javier del. 1993. Teoria y prática de la función poética: poesía siglo XX.

Madrid: Cátedra.

RACIONERO, Luis. 1995. El arte de escribir: emoción y placer del acto creador. Madrid: Temas de Hoy.

SILVA, Lília A. Pereira da. 1991. 33 anos de poesia. São Paulo: Scortecci.

—. 1996. Carnaval Brasil / Carnival Sketches. São Paulo: Scortecci.

—. 1997. Europeanas. São Paulo: Scortecci.

VALÉRY, Paul. 1991. Variedades. São Paulo: Iluminuras.

VERISSIMO, Erico.1999. A liberdade de escrever: entrevista sobre literatura e política. São Paulo: Globo. 